
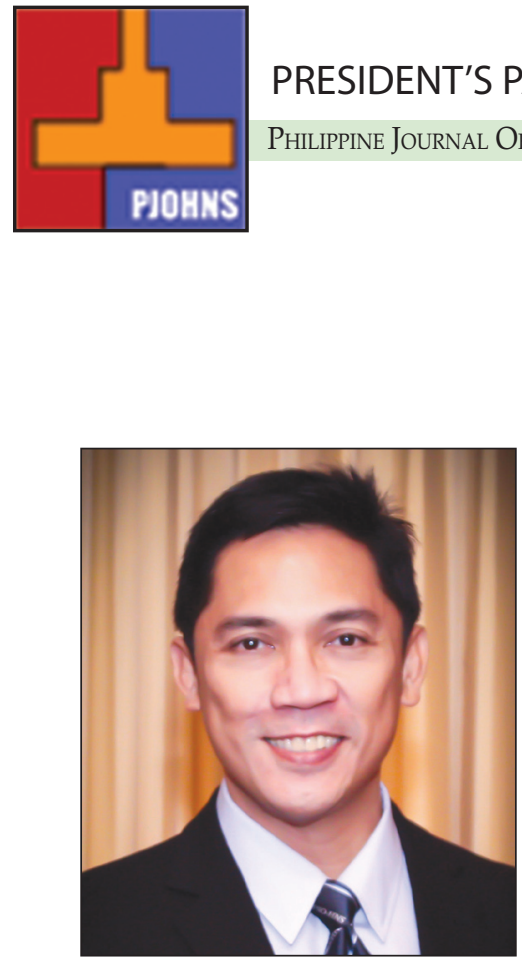

\title{
Onwards to our 61st Year of Existence!
}

Soaring high on the heels of our just-concluded Jubilee Year, the Philippine Society of Otolaryngology-Head and Neck Surgery is very proud of its strides in the fields of service, education, training, and -- with the Philippine Journal of Otolaryngology-Head and Neck Surgery (PJOHNS) as its documentation and publishing arm, it is now a force to reckon with in-- research!

The PJO-HNS is in a continuous journey of improvement and development into an open access journal, which will benefit our trainees, diplomates and fellows, and open our research work to be more accessible on the international scientific stage. We laud the continued efforts of our training institutions in pushing for their respective research agendas.

We must also look forward the constitution and operationalization of an IRB (for PSO-HNS to make its own Institutional Review Board) to approve, monitor and review biomedical and behavioral research conducted by our fellows, who may not have any tie-up or affiliation with established training institution. This is one area which the Editorial Board led by Dr. Jose Florencio Lapeña and the Board of Trustees are seriously looking into.

Congratulations to the contributing authors of this issue and more power to the PJO-HNS!

MELFRED L. HERNANDEZ, MD, MHA

President

Philippine Society of Otolaryngology-Head and Neck Surgery 